\title{
Jurnal
}

\section{CONTINUITY OF GREAT SUMATRAN FAULT IN THE MARINE AREA REVEALED BY 3D INVERSION OF GRAVITY DATA}

Yanis Muhammada*, Abdullah Faisala,b, Assyifa Yennya, Zainal Muzakira, Marwan Abubakara, Ismail Nazlia,b

aGeophysical Engineering Department, Universitas Syiah Kuala, Darussalam-Banda Aceh 23111, Indonesia

bPhysics Department, Universitas Syiah Kuala, Darussalam-Banda Aceh 23111 , Indonesia
Article history

Received

2 April 2020

Received in revised form

28 November 2020

Accepted

2 December 2020

Published online

17 December 2020

*Corresponding author yanis@unsyiah.ac.id

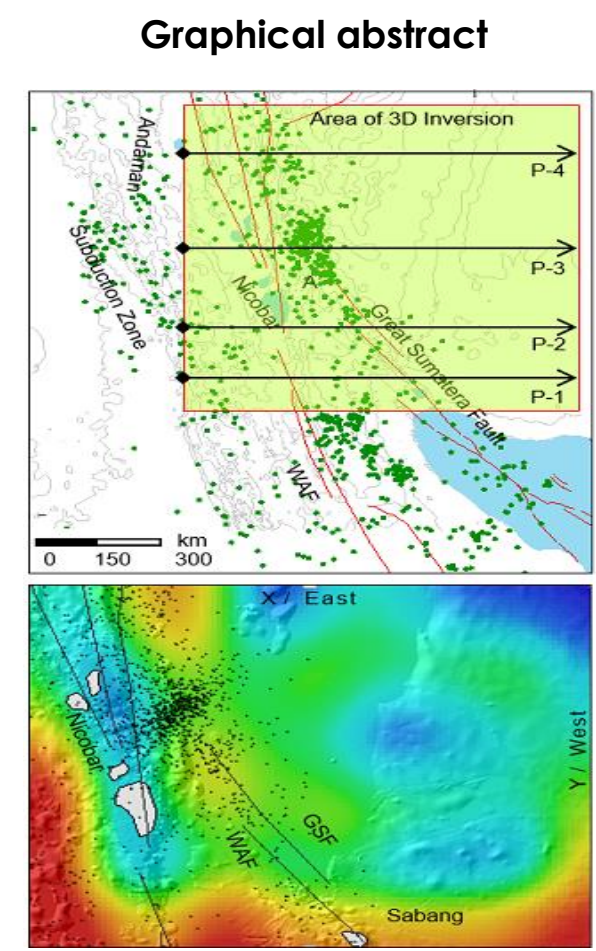

\begin{abstract}
The Great Sumatran Fault (GSF) is a 1900-km-long fault extending from Lampung, Indonesia, to India's Andaman Islands. The fault location is not only on the land but also in the marine area. Previous studies were only focused on the land area of Sumatra and Andaman Islands even though the marine fault has also impacted earthquakes and tsunamis such as in 2004. As an effort to disaster risk mitigation, this study used the gravity method to map and study the continuity of the GSF in the marine area from the Aceh Province, Indonesia, to the Andaman Islands, India. The gravity data were obtained from Topex with a resolution of $1.85 \mathrm{~km} / \mathrm{px}$. Based on the Bouguer data, the subduction zone in the western part of the Indian Ocean is observed with the anomaly of $500-700$ mGal, while the residual structure of GSF, relative to the subduction zone, only comes to clarity through a horizontal derivative transformation with anomaly 130-250 mGal. To delineate the fault's geometry, the data were inverted by GRABLOX 1.6 using Singular Value Decomposition and Occam methods. The 3D modeling results also clearly show the contrast density between regional faults such as subduction zones on the Westside of the West Andaman Fault (WAF). The GSF faults can also be well demonstrated at $50 \mathrm{~km}$ depth. Based on these results, the gravity Topex is potentially used as a preliminary study of the GSF activity in the marine area.
\end{abstract}

Keywords: Great Sumatran Fault, Andaman Fault, Gravity Satellite, Derivative 3D Gravity Inversion, disaster mitigation

(C) 2021 Penerbit UTM Press. All rights reserved

\subsection{INTRODUCTION}

Indonesia is exceptionally prone to earthquake events because it is being at the intersection of Indo-Australia, Eurasia, and the Pacific plate, actively shifting past one another. The plate's activity is performed by the Great Sumatran Fault (GSF) that extends about 1900 $\mathrm{km}$ from Lampung to the Andaman Sea. Such a long fault system splits into 20 segments. The seismic activity along the GSF has been studied extensively, primarily on the ground using geological and geodetic studies [1] and active fault mapping along the Sumatran fault trajectory based on seismological and geomorphological data [2], [3]. 
The GSF slip rate in the Aceh region is also predicted to be at $3.8 \mathrm{~cm} / \mathrm{yr}$ using geodetic data [4]. By far, the GSF studies have been predominated and focused on the land area [5], while the continuity of the GSF in the marine area that extends to the Andaman Islands has been rarely studied [6]. In reference to the seismic activities data derived from United States Geological Survey [7], the earthquakes of a wide range of magnitudes have taken place in the Andaman Sea from 1980 to 2020 by $M w>3$ (Figure 1). The seismic activity is more dominant on the sea area than on the mainland of Sumatran Island. Therefore, as an effort to disaster mitigation, it is necessary to conduct a geophysical study to delineate the GSF and study the geometry structure in the marine area.

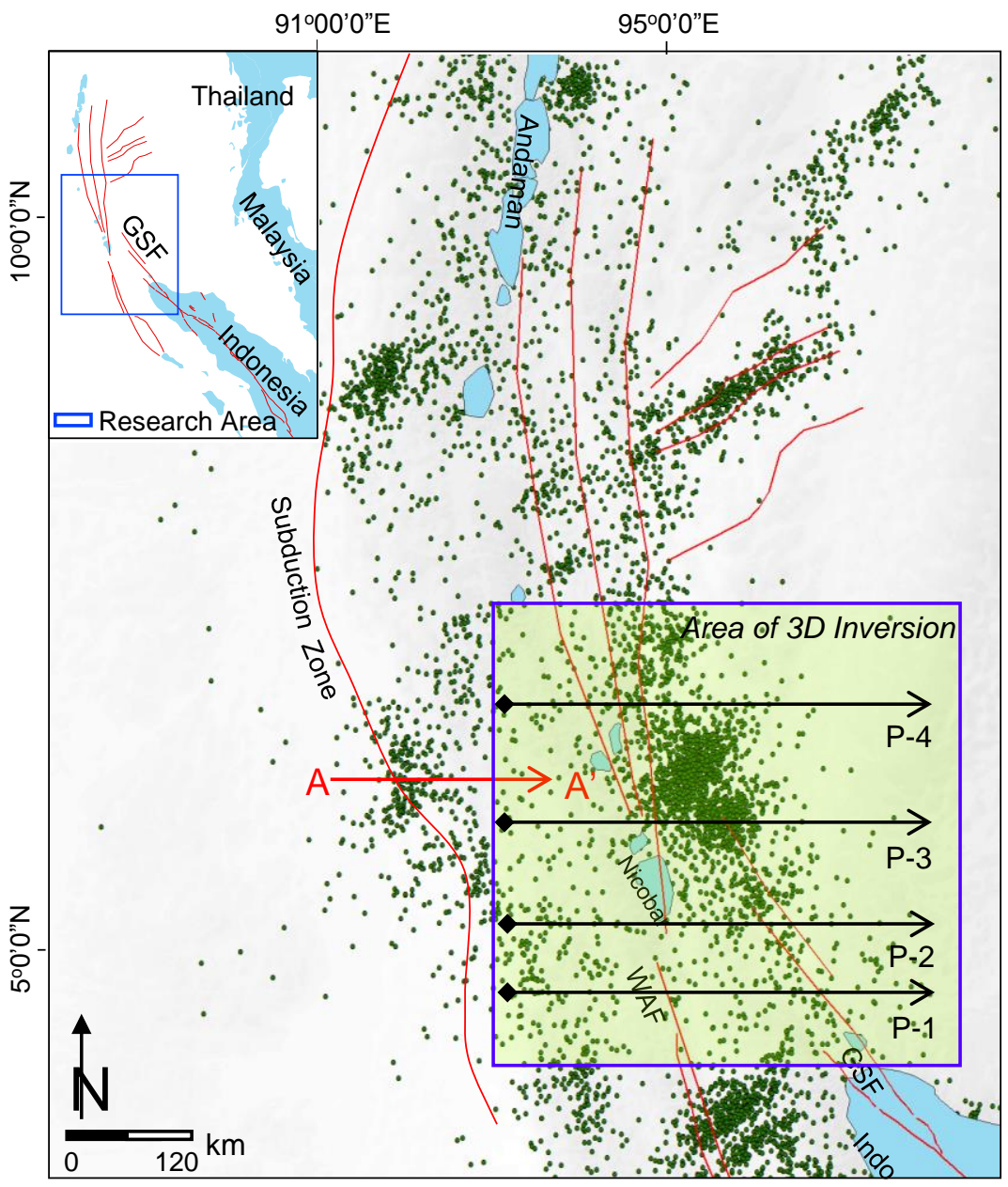

- Earthquake data > Mw 1 from USGS ( 1980 - 2020)

Figure 1 Seismic activity spread within the Sumatran sea area overlaid by bathymetry data from GEBCO. The green dot is earthquakes of magnitudes greater than Mw 1. Earthquake data are derived from USGS in 1980-2020. The A-A' is a profile representing the 2D slice area to see the earthquake depth shown in Figure 3 . And the blue box is an area that is used for 3D inversion, while $P$ symbols are a cross-section profile from 3D inversion

A variety of geophysical methods have been used to estimate fault structures on the marine area; such as the application of the seismic reflection to map the Anatolian faults in the Aegean Sea, Turkey [8], combining of high-resolution aeromagnetic and seismic reflection for mapping Seattle fault zone in North America [9], the marine magnetic method for mapping Northern segment of the North Anatolian Fault, Turkey [10], seismology and geodetic as applied in Letojanni fault system, Italy [11]. All of the conventional methods can map well the fault structure in the subsurface. But on the other hand, it requires much time and is expensive for acquiring the data, installing the seismograph and geodetic stations, and involves many people in data collection. Moreover, the geophysical methods were developed, which can be acquired through satellite. One of them is gravity anomaly [12]. The gravity method was also applied for fault mapping in some other locations, such as in Nigata, Japan [13] and the Trøndelag Fault in Norway [14]. The gravity method is regarded as a geophysical method with the highest effectiveness for fault structure delineation [12]. The gravity method uses gravity anomalies due to differences in 
subsurface rock densities. For bigger-scale surface applications, the technique lacks its potential to be implemented. It is time-consuming and costineffective in its operation, especially in a marine area that applied different gravity instruments than used in the ground survey. Therefore, gravity data are not only acquired using ground-based instruments but can also be measured with airborne and spaceborne instruments. According to Kaye [15], some gravity satellites of various resolutions can be used freely, i.e., Topex (NASA) and Poseidon (CNES) satellites with a resolution of $1.5 \mathrm{~km} /$ pixel [16]. The research results by [16] showed that satellite data response is associated with the marine gravity data derived by ship-borne measurements in Indian offshore, and [17] in the East Sea, Korea.

The gravity satellites have also been specifically applied in several locations in Indonesia, for example, in the basin mapping in the hydrocarbon fields on the East Islands, Timor - Timor Indonesia [18] and Tanimbar, Maluku [19]. The results obtained correspond to ground-based gravity measurement. The gravity satellite data also used to delineate the Seulimeum and Aceh segments' structure in Sumatran Island [20]. For another case, gravity is also efficient to study the small object, i.e., archaeology [21], [22]. In this research, we study a potential use of the satellite gravity data in mapping the structure of the GSF in the marine area, which extends from Aceh Province (Indonesia) to the Andaman Islands (India).

This study's gravity data were obtained from the Scripps Institution of Oceanography, University of California, San Diego. The satellite gravity data analysis has been proven effective in early sub-surface geological mapping in hard-to-reach areas [23]. This study aims to implement the vertical and horizontal derivatives as an interpretation technique to improve the linear trend of the gravity data. In order to delineate the fault geometry in the subsurface, 3D gravity was inverted using the singular Value Decomposition (SVD) and Occam modeling [24]. To solve the ambiguity of gravity inversion, the models were combined with the geological fault structure obtained from several previously published studies in the areas stretching from Sumatera to the Andaman Sea as a constraints model [6], [25], [26].

\subsection{MATERIAL AND METHODS}

Gravity is one of the geophysical methods for measuring anomalies in the earth's gravitational field due to differences in sub-surface rock densities. The gravity method is based on Newton's law that the magnitude of the force of attraction between two objects is directly proportionate to mass and inversely proportional to the square of the distance from one object's focal point to the other [27]. Mathematically it can be written with the equation [28]:

$$
F=G \frac{m_{1} m_{g}}{r^{2}}
$$

$F$ is the force between two objects, $G$ is the constant of gravity $\left(6.67 \times 10^{-11} \mathrm{Nm}^{2} / \mathrm{kg}^{2}\right), m_{1}$ and $m_{2}$ are the mass of the objects, while $r$ is the distance between the mass centers of the two objects. In the fields, the physical parameters of the methods can be influenced by several factors, such as differences in elevations, latitudes, and weather, which needed to be corrected with the so-called standard corrections such as the tide, drift, free-air, Bouguer, and topographic corrections. The gravity method is a common application (2D or 3D) in a range of early explorations to study structures on either a regional scale, such as fault and basin [20], [29] or a local scale such as a shallow anomaly in archeology site [21], [22].

Based on the concept measurement [17], The gravity method does not require direct contact with the ground surface, which allows for acquisition through ground-based, ship-borne, airborne, and satellite with various instrumentation sensors. The shipborne instrument is a gravity sensor used for marine surveys, but the operation in the field surveys is uneconomical. In this study, we introduce a low-cost method to examine sub-surface structures in the marine area. We used free-air anomalies data from Topex (NASA) and Poseidon (CNES) altimeter with transformation and $3 \mathrm{D}$ data inversion technique to enhance the edge boundaries of sub-surface fault structures. The Topex altimeter satellite works at the frequencies of $5.3 \mathrm{GHz}$ and $13.6 \mathrm{GHz}$, while the Poseidon altimeter satellite at $13.6 \mathrm{GHz}$ only. A comparison between the two satellites produces freeair anomaly data at a resolution of $1.85 \mathrm{~km} / \mathrm{px}$, which accessible from http://topex.ucsd.edu [30].

The satellite imageries of gravity anomalies within the Andaman region were obtained from the Topex website with coverage spanning from $91^{\circ} \mathrm{E}$ to $97^{\circ} \mathrm{E}$ and $2^{\circ} \mathrm{N}$ to $15^{\circ} \mathrm{N}$. The free-air anomalies obtained from the satellite was in the ASCII-XYZ format [16], covering 285.552 data points. The free-air anomaly data range from -90 to $125 \mathrm{mGal}$, where the West and East sides are dominated by low values and are relatively high values in the middle area of the survey area. Figure 2 shows the free-air anomaly data obtained from the research area. However, the free-air data have not yet to be applicable for the geological structure interpretation as they are solely associated with changes of surface topographic or bathymetric height [16].

Free air anomaly in the gravity method is a gravitational acceleration parameter that only associates to the topographical conditions of the study area [31], which requiring Bouguer and terrain corrections in order to acquire complete Bouguer anomaly data based on sub-surface anomalies. This research also used the seismicity data from the United States Geological Survey (USGS) from the magnitude 1 to $10 \mathrm{MW}$, which was acquired from 1980 to 2020. The acquired data of the Topex and Poseidon satellite were in the form of fee-air anomalies associated with the sea level data; the data need to be converted to a flat sphere by Bouguer correction. 


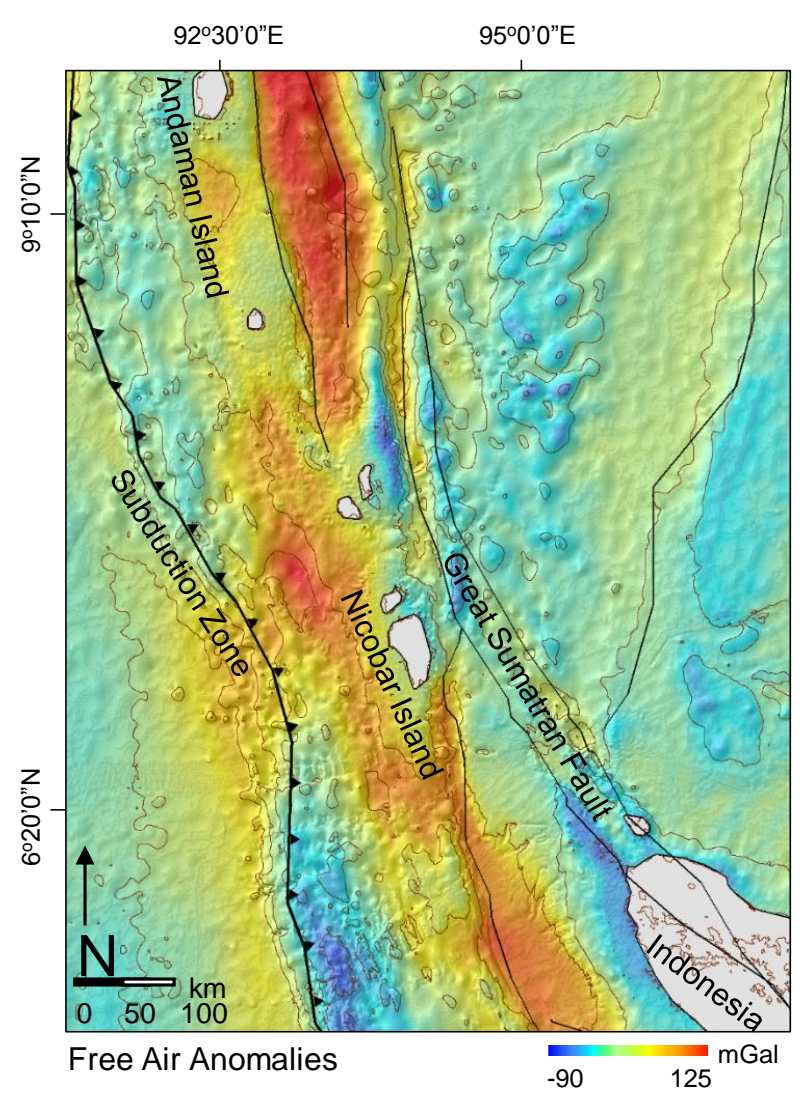

Figure 2 Free air gravity that extracts from TOPEX Satellite. The data only associated with topography or bathymetry. A correction technique is needed for the data before use for interpretation

In contrast to ground gravity, which requires several standard corrections such as drift, tidal, and latitude to obtain free air data [17], [27]. The gravity satellite only needs to be corrected by Bouguer and terrain to get a complete Bouguer anomaly. This is because satellite data is already available in a free-air anomaly. The Bouguer correction was performed to calculate the rock mass between the data station and the geoid sphere [24]. This correction computes the gravity data caused by rocks in the subsurface, which have an average thickness and density. In the correction process, an assumption of density contrast in the research area is needed. This information can be obtained through geological maps showing the dominance of rocks in the survey area. In this study, we used the rock density contrast for $2.67 \mathrm{gr} / \mathrm{cm} 3$ as a response to the igneous rock of the oceanic crust, as has been done in several studies in the Andaman area [25], [32].

Besides, the Bouguer anomaly data also need to be corrected with the topographic correction by Hammer's chart method [33]. The correction of the terrain was performed due to the irregular distribution of the mass around the survey area. In Bouguer correction, it is assumed that the data measurement is on a flat sphere, whereas in reality, the topography or bathymetry of the place is not flat. Furthermore, to obtain a complete Bouguer anomaly, the terrain correction must be applied to gravity data. The data topographic/bathymetry used as a parameter in terrain correction is obtained from the General Bathymetric Chart of the Oceans (GEBCO), which provides the global coverage bathymetry on a 15 arcsecond.

In several cases, the Bouguer gravity anomaly is challenging to interpret the geological structure in the subsurface. It is due to affected by the regional, residual anomaly and also caused by slow tectonic movements. In the gravity method, various techniques are available to detect edge boundaries in gravity field anomalies generated by geological structures; even today, edge detection constitutes a critical step in gravity data interpretation [34]. The vertical derivative is the first transformation technique applicable to finding the edge boundaries of each sub-surface geological structure. It is typically applied to gravity data to delineate near-surface geological features and to enhance high-wavenumber components of a spectrum. The zero values of the vertical derivative of gravity data usually correspond to geological boundaries [35]. The mathematically vertical derivative is given below:

$$
V D=\left(\frac{\partial \Delta T}{\partial z}\right)
$$

$T$ is Bouguer gravity data and $\partial z$ is gravity in the vertical z-direction, and VD is a vertical derivative in $\mathrm{mGal} / \mathrm{m}$. Hence, the transformation of this sort can be used to map sub-surface geological and fault structures. However, due to more lineaments structure are shown by this data, vertical derivatives are still difficult for mapping the fault in the subsurface. Thus, a horizontal transformation calculates the horizontal plane gradient with $\partial T / \partial x$ in the $x$-direction, and $\partial T / \partial y$ as the gravity anomaly derivative in the $y$ direction becomes necessary. The total horizontal derivative method has been extensively used to map the boundaries of gravity density contrast. Mathematically, the horizontal derivative is given below:

$$
H D=\left[\left(\frac{\partial \Delta T}{\partial x}\right)^{2}+\left(\frac{\partial \Delta T}{d y}\right)^{2}\right]^{\frac{1}{2}}
$$

Where $T$ is Bouguer gravity data, and HD is Horizontal derivative in $\mathrm{mGal} / \mathrm{m}$.

\subsection{RESULTS AND DISCUSSION}

\section{Seismicity}

The seismicity study by the USGS in the Andaman Sea shows that from 1980 until 2020, many seismic epicenters were identified, most of which are found in the subduction zone and the GSF. To study the sub- 
surface fault geometry, hypocenter slicing is performed in the area intersecting the subduction zone and the GSF offshore. The hypocenter distribution data are presented in two dimensions, with its longitude as the $x$-axis and its depth as the $y$-axis, depicting the interaction between plate strata structures at which earthquakes occur. The earthquake vertical data profile to depth are presented in detail in Figure 3. The slicing result shows the convergent subduing motion of the Indian Plate underneath the Andaman Plate $50 \mathrm{~km}$ below the surface. This technique was also demonstrated by Radhakrisna (2008) in the Andaman area, which used the seismic activity from 1900 - 2004 [25]. The oceanic plate (Indian) subdues beneath the continental plate (Andaman) as a result of differences in densities, the latter being smaller than the former.

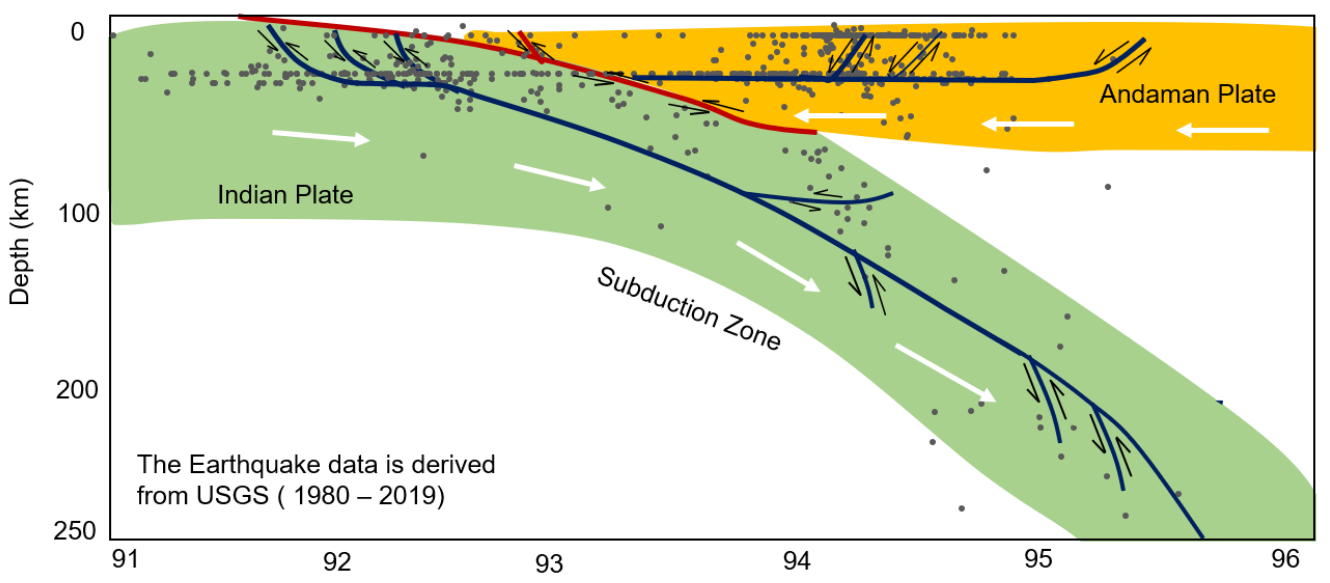

Figure 3 Cross-section from A to $A^{\prime}$ that shows the Vertical earthquake distribution against depth. The green color is the Indian Plate subduing under the Andaman Plate. The blue color is the rupture zone resulted from the earthquake

The collision of the two plates brings about an earthquake. In the long term, recurring seismic activity may lead to ruptures along with every plate. In general, the seismicity hypocenter pattern shows an earthquake distribution at an angle of roughly $50^{\circ}$. The seismicity distribution on the Indian and Andaman plates also brings several local faults out of the pressure from the two colliding plates. The earthquakes on the Indian Plate outnumbered those of the Andaman Plate, resulting in more faults formed on the former.

\section{Bouguer Anomaly}

The lineament structure of the Great Sumatran Fault and Andaman Faut was demonstrated by complete Bouger anomaly, as shown in Figure 4. The Complete Bouguer anomaly data within the research area range are from -100 to $700 \mathrm{mGal}$, where the resolution of the data is also the same as free air anomaly $(1.85 \mathrm{~km} /$ pixel). The western Indian Ocean area is dominated by low anomalies (-200 to $50 \mathrm{mGal}$ ), while the orange-red color marks the higher-range zones at approximately 300 to $450 \mathrm{mGal}$. These high Bouguer values are a response to undersea fault anomalies, with the patterns in the west and the east corresponding to the geological structure of the Sumatran Fault and the subduction zone. Black lines are fault locations based on several publications. The black triangle is the subduction zone.

The Bouguer gravity anomalies of the Andaman Islands and Nicobar are at high values, indicating that both were formed out of a collision between the
Indian and the Sumatran plates. In general, the Bouguer gravity data can demonstrate a contrast between the subduction zone and the surrounding regional areas. Still, for the Sumatran fault, the data have yet to show such contrast. Thus, it is necessary to perform the edge detection method to clear the subsurface geological and fault structures.

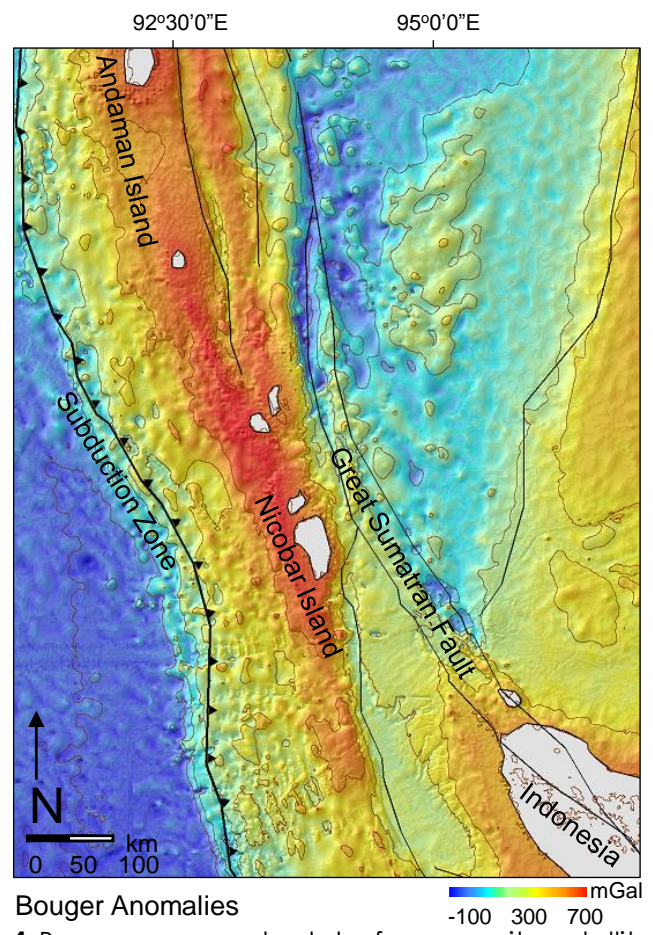

Figure 4 Bouguer anomaly data from gravity satellite in the marine area from Sumatera to Andaman 


\section{Gravity Transformation}

The horizontal and vertical derivatives have been used to evaluate the effectiveness of edge techniques for mapping the lineament structure, which corresponds to a fault and geological in the subsurface. Figure 5.a shows the vertical derivative of the gravity data in $\mathrm{mGal} / \mathrm{m}$. The vertical derivative values range between 1 and $90 \times 10^{3} \mathrm{mGal} / \mathrm{m}$. The data are relatively low on the western and eastern sides of the Indian Ocean and high in the middle. The edge boundary in the west clearly shows the subduction zone and also possible to detect the West Andaman Fault (WAF). In the middle region where the GSF is assumed to lie, only the Aceh segment is clearly shown by vertical derivative data, while the Seulimeum segment is not confirmable. Therefore, the more local areas such as Weh Island, this data does not show the existence of subsurface faults. The same is also seen in fault structures that are close to the Andaman Islands. This factor is caused by vertical derivative data that are not sensitive to structures that are close together because they only calculate the vertical plane $\partial \mathrm{T} / \partial \mathrm{z}$ as the z-direction.

The results obtained by the HD method are considered a quick way to process gravity data to provide accurate information on structural settings, tectonic trends, and depth. These horizontal derivative data are in $\mathrm{mGal} / \mathrm{m}$. Figure 4.b provides the horizontal derivative from the Bouguer anomaly data within the 0-250 $\mathrm{mGal} / \mathrm{m}$ range. Some locations with geological and fault structures are indicated by high and low graduations of the derivative data. According to [36], the maximum horizontal derivative value may get smaller if the fault structure has a gentle slope (nonvertical approaching) or lies in the vicinity of another fault structure. Derivative data can point out a marked contrast between a fault structure and neighboring settings. Not only the regional-natured subduction zone, but the stretch from the Sumatran fault to the Andaman Islands can also be mapped clearly. At the other locations where no geological and fault structures are present, the derivative value stands within the 80-125 mGal.

Horizontal derivative data also represent the distance between one fault structure and another, in which case a low derivative value indicates that there are many geological structures within a given area, and a high value indicates that the faults are sparsely situated from one another. Besides, [34] pointed out that vertical fault structures predominantly have high derivative values. This suggests that the subduction zone is dominated by high derivative, while the Great Sumatran Fault by low derivative. The overall transformation of this tilt derivative is able to map the structures of the fault and subduction zone within the Indian Ocean area. Even the data obtained are open to direct interpretation, albeit without geologically structure overlay. The horizontal derivative also shows that the Great Sumatran Fault extends to the Andaman Islands, with the Weh Island situated right in the Sumatran fault trajectory, while the Andaman Islands $50 \mathrm{~km}$ away from the GSF. To study the geometry of the subduction zone and the Sumatran fault, 3D modeling of the gravity data is performed at a location that crosses the two structures.
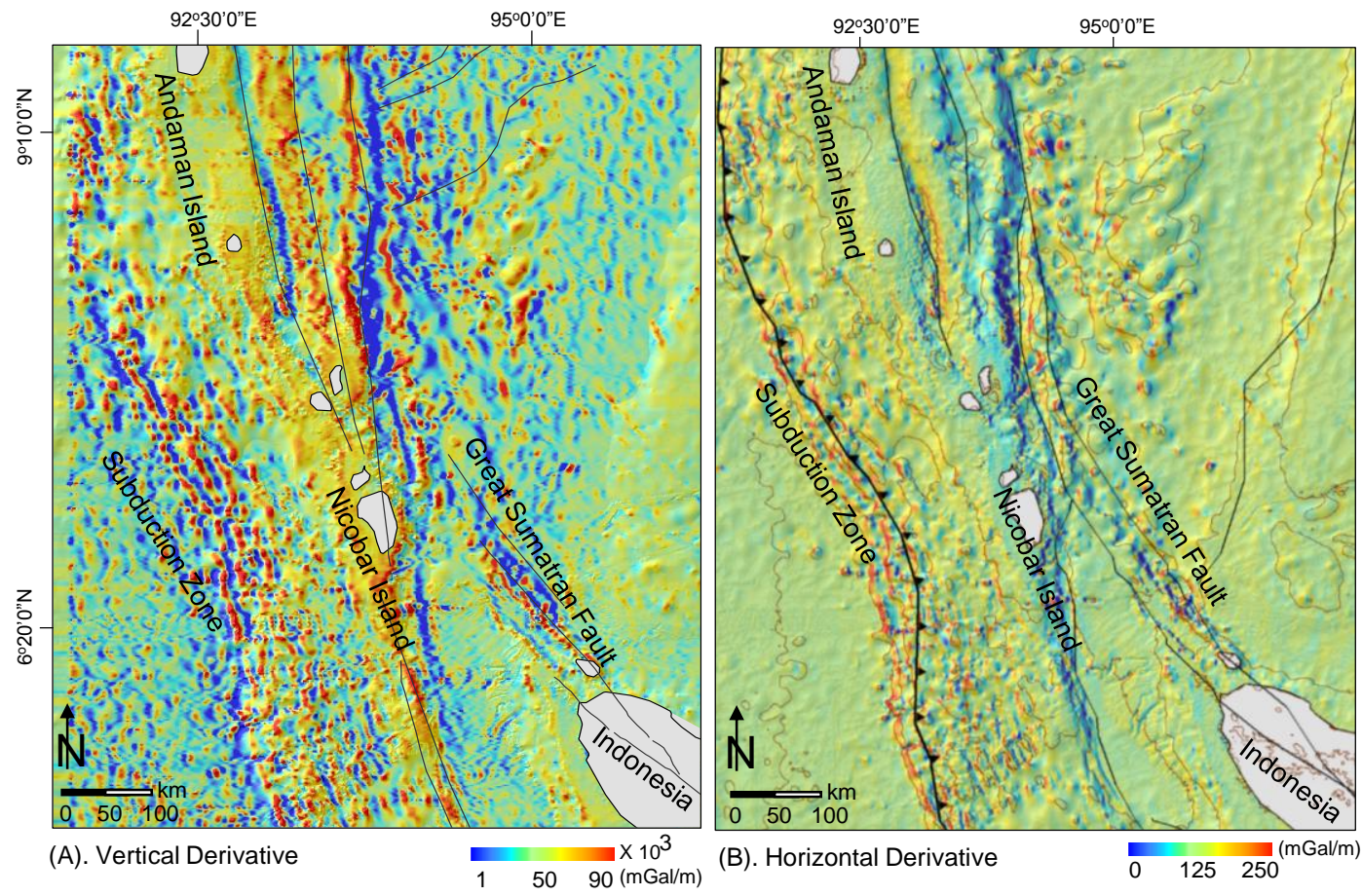

Figure 5 Vertical and Horizontal Derivatives data to delineate the Sumatran fault contrast in the marine area. The fault structure is generally indicated by the graduation change of high and low derivative values, while no structure is characterized by a medium derivative value 


\section{Inversion of 3D Gravity Data}

To study the fault's geometry in the subsurface, we inverted the 3D gravity models with the forward modeling approach and integration of the geological setting as a constrains model. The 3D gravity models were inverted using GRABLOX 1.6, developed by Pittijarvi [37]. GRABLOX measured the gravity anomaly as synthetic of the large rectangular superblock, divided into smaller columns like volume elements. The software combines two inversion methods; Singular Value Decomposition (SVD) and Occam inversion, which is processed sequentially [24]. The SVD method is a powerful technique that has been used in the analysis of matrices in many fields. In contrast, Occam is an inversion method that utilizes the roughness level of the model. This method is often applied in magneto-telluric data processing [38] and possible to use in gravity data [24].

The data used in the inversion process is a Bouguer anomaly with several considerations; the research location is a large area, the anomaly studied is regional, and the satellite data resolution is also relatively regional, so the Bouguer data does not need to be converted to a residual anomaly. One of the classic problems in gravity inversion is the high data ambiguity; we used the depth penetration model based on the analysis of seismicity data from 1980 2020 obtained from USGS. Overall, the maximum depth of an earthquake is up to $250 \mathrm{~km}$ in the subsurface. Still, only at a depth of $0-200 \mathrm{~km}$, which
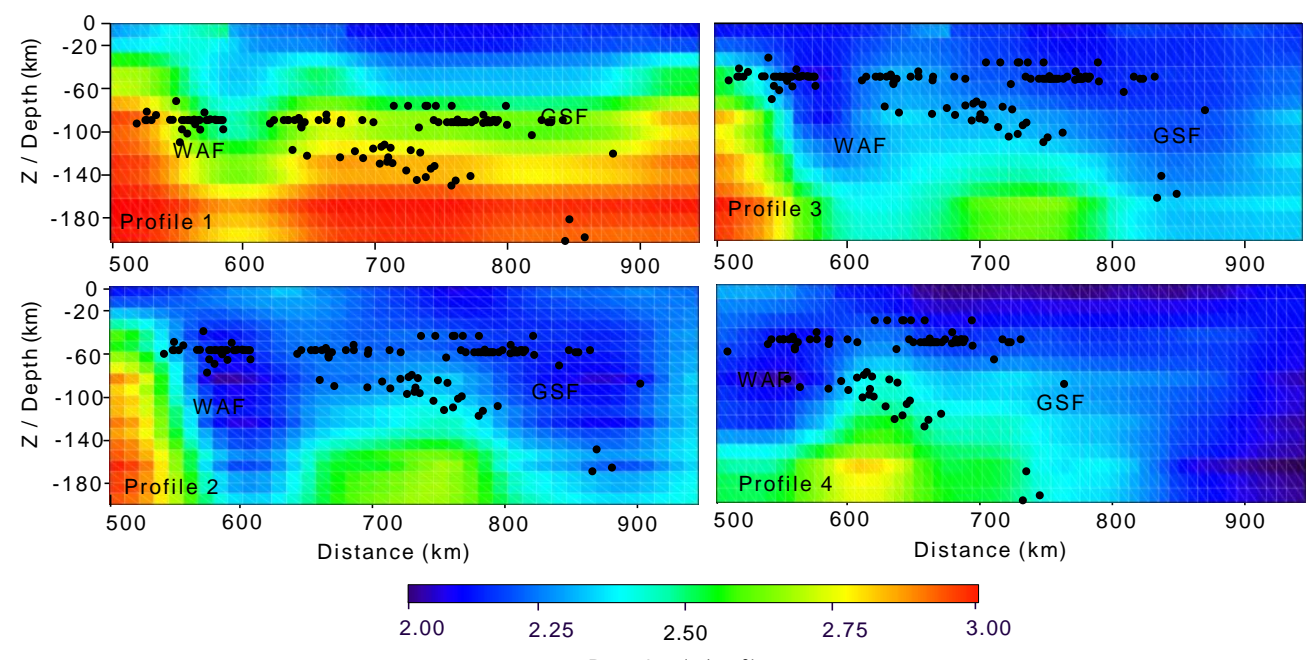

Figure $62 D$ gravity across the section from 3D inversion, the data also overlaid with the earthquake event $>1 \mathrm{MW}$ that derived from USGS

The results of 3D modeling show the subsurface model to a depth of $180 \mathrm{~km}$. This section model was made by crossing the structure of the West Andaman Fault on the west side and the Great Sumatran Fault on the middle side. In the profile 1 shows three density contrast zones, where the third layer from a depth of $140-200 \mathrm{~km}$ is dominated by a density of $3 \mathrm{~g} / \mathrm{cm}^{3}$, while a density of $2 \mathrm{~g} / \mathrm{cm}^{3}$ is obtained at shallow has a relatively more earthquake distribution, the 200 $\mathrm{km}$ of the depth is used in model assumption and the Bouguer anomaly in $\mathrm{mGal}$ as the input parameter for inversion of 3D gravity. Furthermore, the geological constraints (density values) are used in the range of 2 $3 \mathrm{~g} / \mathrm{cm}^{3}$. This density is obtained from the 2D modeling of gravitational data in the Andaman Islands that are relatively close to the study area [25], where the water layer is $1.03 \mathrm{~g} / \mathrm{cm}^{3}$, crust $2.7 \mathrm{~g} / \mathrm{cm}^{3}$, and mantle 3.3 $\mathrm{g} / \mathrm{cm}^{3}$. The contrast of background density, i.e., 2.1 and 2.67, was selected for modeling the GSF structure. These bodies are related to sedimentation rock.

Another problem in 3D gravity modeling is the relatively high memory space requirements, so we only do inversions in selected areas that cover the GSF and West Andaman Faults (WAF) on the western side of the Andaman Islands (in Figure 1 show by the blue box). The number of block matrices used in the inversion is $60 \times 50 \times 15$ as a function of latitude (X), longitude (Y), and depth (Z). By using a Core i5 and 8 GB RAM, it takes more than 10 hours for the running process for Occam and SVD methods. The block was discretized by grid block with dimensions of $4.47 \mathrm{~km}$ and $4.58 \mathrm{~km}$ in the direction of the E-W and N-S. The RMS error of the model is $0.7 \mathrm{mGal}$, and the maximum difference between observed and calculated data is $10 \mathrm{mGal}$ after 5 iterations. To study the geometry structure of the fault, the 2D profile in the W-E direction was sliced in the four areas that corresponded to the GSF strike obtained from the bathymetry data, as shown in Figure 6.
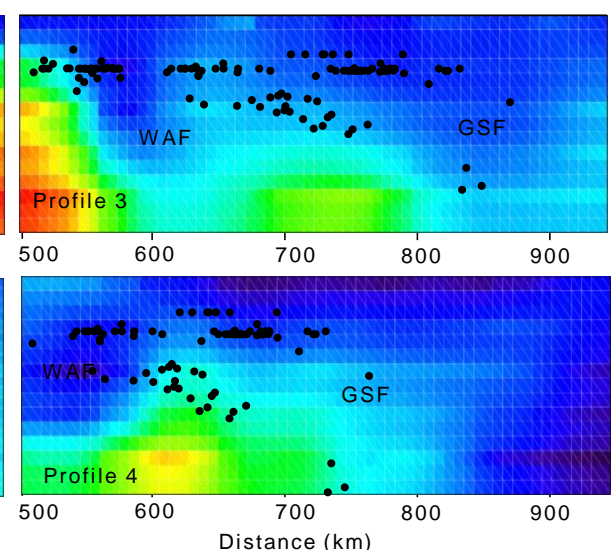

$\left(\mathrm{cm}^{3}\right)$ 
friction of two plates (Andaman and Sumatran) and caused the accumulation of energy released when it reaches maximum stress. In profile 2 , a density of 2.5 $\mathrm{g} / \mathrm{cm}^{3}$ is estimated as a WAF structure. The depth of WAF and GSF fracture was obtained for $200 \mathrm{~km}$ in the subsurface that also corresponds to the epicenters of the fault. Besides, at a distance of $650-800 \mathrm{~km}$, there is a bolder with a density of $2.5 \mathrm{~g} / \mathrm{cm}^{3}$. This anomaly can be interpreted as a tectonic response of the Nicobar Islands, India. In profile 3 the response is relatively the same as profile 2 , it caused both profile slices is in the close area. While in profile 4, the GSF structure leads to the West Andaman fault in the Westside. Furthermore, the earthquake epicenter at this location is predominantly in one direction as a response to tectonic activity from both faults.

The results of 3D modeling show the subsurface model to a depth of $180 \mathrm{~km}$. This section model was made by crossing the structure of the West Andaman Fault on the west side and the Great Sumatran Fault on the middle side. In the profile 1 shows three density contrast zones, where the third layer from a depth of $140-200 \mathrm{~km}$ is dominated by a density of $3 \mathrm{~g} / \mathrm{cm}^{3}$, while a density of $2 \mathrm{~g} / \mathrm{cm}^{3}$ is obtained at shallow depth. The WAF fault structure is shown by low-density contrast at a distance of $600 \mathrm{~km}$, and the GSF
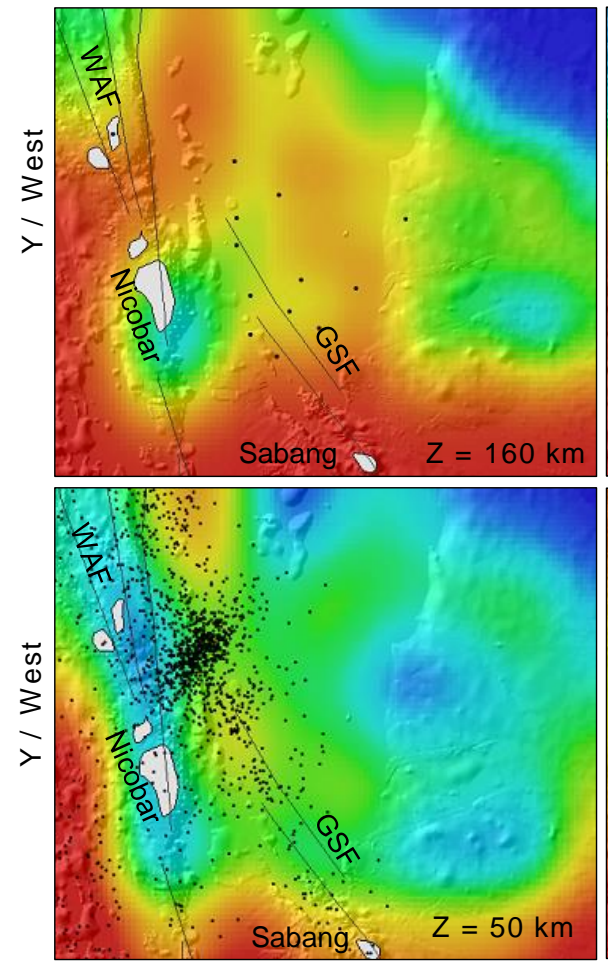

X/ East possible to detect at a distance of $850 \mathrm{~km}$. Both of these faults are at a depth of $50-150 \mathrm{~km}$ in the subsurface. The depth also corresponds to the hypocenter of the earthquake, which predominantly at a depth of $50-150 \mathrm{~km}$, and also forms a fault pattern of GSF. A lot of seismicities occurred due to friction of two plates (Andaman and Sumatran) and caused the accumulation of energy released when it reaches maximum stress. In profile 2 , a density of 2.5 $\mathrm{g} / \mathrm{cm}^{3}$ is estimated as a WAF structure, the depth of WAF and GSF fracture was obtained for $200 \mathrm{~km}$ in the subsurface that also corresponds to the epicenters of the fault. Besides, at a distance of $650-800 \mathrm{~km}$, there is a bolder with a density of $2.5 \mathrm{~g} / \mathrm{cm}^{3}$, this anomaly can be interpreted as a tectonic response of the Nicobar Islands, India.

In profile 3 the response is relatively the same as profile 2; it caused both profile slices is in the close area. While in profile 4, the GSF structure leads to the West Andaman fault in the Westside. Furthermore, the earthquake epicenter at this location is predominantly in one direction as a response to tectonic activity from both faults. To study the structure of the Great Sumatran Fault on the seaside, we present 3D gravity modeling that is overlaid with earthquake data, as shown in Figure 7.
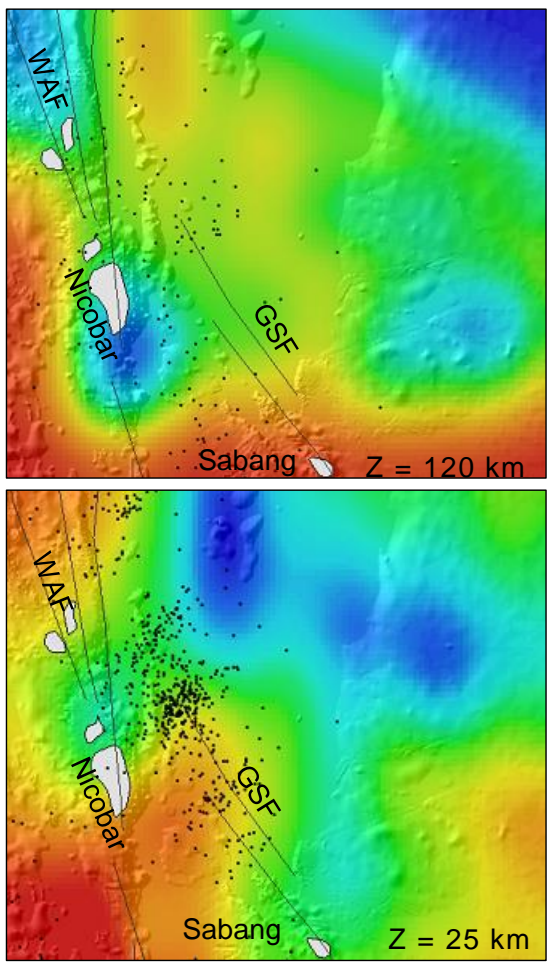

X/ East

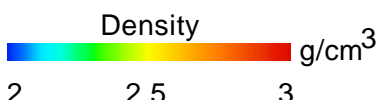

$2 \quad 2.5 \quad 3$

Figure 6 The 3D model of gravity inversion, the model also overlays with the seismicity data (black dots) at a relatively similar depth to the density model. The seismicity data is from 1989 to 2020 with magnitudes starting from Mw 1 
The 3D models are presented in different depths, as well as seismicity data plotted according to the gravity model depth. In general, a relatively high density is on the West side of the 3D inversion area, while the Eastside is obtained by a low density, at a depth of $160 \mathrm{~km}$ from the inversion model, the contrast density does not correspond to the GSF and WAF fault structures.

The model is in response to a deeper regional anomaly i.e., subduction zone, which collides with the Andaman plate. The hypocenter seismicity data also showed at this depth, and there was no significant tectonic activity from both faults. Whereas at a depth of $120 \mathrm{~km}$, the 3D model shows a very clear contrast between the WAF fault and the subduction zone area on the Westside. This anomaly is clearly shown caused by the Indian Plate (oceanic crust) has a different density than Andaman Plate (continental crust). Furthermore, the Sumatran faults in the shallow depths cannot be shown by the density model in this depth because GSF and WAF structures have the same relative low density $\left(2 \mathrm{~g} / \mathrm{cm}^{2}\right)$. The seismicity data plotted at depths of $100-120 \mathrm{~km}$ also show a small distribution of the earthquake events.

In a depth of $z=50 \mathrm{~km}$, the 3D gravity model can show very clearly more faults structure in the subsurface, both regional and residual anomaly, such as the boundary structure of the subduction zone (Indian Plate and Andaman plate) on the Eastside, the structure also corresponds to the earthquake data distribution that plotted in the depth of $40-75$ $\mathrm{km}$. The West Andaman Fault is also shown by a very contrasting density $\left(2 \mathrm{~g} / \mathrm{cm}^{3}\right)$ extending from the Nicobar Islands to the Andaman Islands. More earthquake events at this depth also show the tectonic activity from the fault. While the Great Sumatran Fault in the middle of the 3D area is characterized by relatively high density $\left(2.5 \mathrm{~g} / \mathrm{cm}^{3}\right)$, the GSF is moving sideways from the Weh Island, Indonesia, and coinciding with the West Andaman Fault in the Andaman Islands. This also describes more seismicity over the Nicobar Islands, India. In a shallow depth of the model $(z=25 \mathrm{~km})$, the contrast density of the 3D inversion does not indicate the subduction zones and WAF faults on the Westside. This density model is only responses to the Nicobar Islands. Whereas in more seismicity data such as the Sumatra Fault, the 3D model can show the fault structures in the subsurface.

\subsection{CONCLUSION}

We use the 3D inversion and transformation of gravity satellites to delineate the Great Sumatran Fault (GSF) structures in the marine area. In general, the research of the marine area is required an expensive technology. But in this study, we performed a low-cost method to study the deep structure of the GSF and West Andaman Fault (WAF) that in the subsurface. We used the gravity satellite, namely Topex with a resolution of $1.85 \mathrm{~km} / \mathrm{px}$. Bouguer anomaly from satellite data shows the contrast difference between the subduction zone and WAF on the West side of the Andaman Islands, but for the residual structure, the GSF can only be shown by derivative data. The vertical and horizontal derivatives can clearly show the transforming movement of WAF fault and GSF structure to the Nicobar and Andaman Islands. Another fault in the Andaman area can also be delineated through this technique, which is characterized by contrasting differences in values from low to high anomaly data.

A cross-section from the 3D model shows the structure of GSF at a depth of $50 \mathrm{~km}$ in the subsurface, which correlates to seismicity from USGS data. The overall 3D model that has been plotted at different depths and overlaid with hypocenter of the earthquake with the depth of the model shows at a depth of 25 - $50 \mathrm{~km}$; the existence of GSF and WAF are shown clearly with different densities. This can also be demonstrated by the relatively more seismic distribution. Based on the results, we concluded the gravity satellite is potentially used as an economical method to study the fault's detailed structure in the marine area. While the derivative technique also allows for imaging a lineament structure and responds to the regional and residual anomaly, which corresponds to a fault and geological structure in the Andaman area. However, due to ambiguity in 3D gravity inversion, this method requires other supporting data, such as the seismicity and geological information applied in this research.

\section{Acknowledgment}

The author would like to thank Nuzul and Yenni Asyifa for the considerable assistance during the gravity data processing, and to Badrul Munir as the Geophysical Modelling Laboratory assistant for providing the computer and software for the data processing. This research is part of the Lector grant from Universitas Syiah Kuala, Indonesia, by number No. 189/UN1 1.2.1/PT.01.03/ PNBP/2020.

\section{References}

[1] K. Sieh and D. Natawidjaja. 2000. Neotectonics of the Sumatran Fault, Indonesia. J. Geophys. Res. Solid Earth. 105(B12): 28295-28326.

Doi: $10.1029 / 2000$ JB900120.

[2] U. Muksin et al. 2019. AcehSeis Project Provides Insights into the Detailed Seismicity Distribution and Relation to Fault Structures in Central Aceh, Northern Sumatra. J. Asian Earth Sci. 171: 20-27.

Doi: 10.1016/j.jseaes.2018.11.002.

[3] Marwan, Asrillah, M. Yanis, and Y. Furumoto. 2019. Lithological Identification of Devastated Area by Pidie Jaya Earthquake through Poisson's Ratio Analysis. Int. J. GEOMATE. 17(63): 210-216.

Doi: 10.21660/2019.63.77489.

[4] T. Ito et al. 2012. Isolating Along-strike Variations in the Depth Extent of Shallow Creep and Fault Locking on the 
Northern Great Sumatran Fault. J. Geophys. Res. Solid Earth. $117(\mathrm{~B} 6)$.

Doi: $10.1029 / 2011 \mathrm{JB} 008940$.

[5] O. Weller et al. 2012. The Structure of the Sumatran Fault Revealed by Local Seismicity. Geophys. Res. Lett. 39: L01306.

Doi: 10.1029/2011GL050440.

[6] D. Ghosal, S. C. Singh, A. P. S. Chauhan, and N. D. Hananto. 2012. New Insights on the Offshore Extension of the Great Sumatran Fault, NW Sumatra, from Marine Geophysical Studies. Geochemistry, Geophys. Geosystems. 13(1). Doi: 10.1029/2012GC004122.

[7] US Geological Survey. 2020. Earthquake Catalog. https://earthquake.usgs.gov/earthquakes/search/ (accessed Jan. 01, 2020).

[8] A. Janin, M. Rodriguez, D. Sakellariou, V. Lykousis, and C. Gorini. 2019. Tsunamigenic Potential of a Holocene Submarine Landslide along the North Anatolian Fault (northern Aegean Sea, off Thasos island): Insights from Numerical Modelling. Nat. Hazards Earth Syst. Sci. 19: 121136.

Doi: 10.5194/nhess-19-121-2019.

[9] R. J. Blakely, R. E. Wells, C. S. Weaver, and S. Y. Johnson. 2002. Location, structure, and Seismicity of the Seattle Fault Zone, Washington: Evidence from Aeromagnetic Anomalies, Geologic Mapping, and Seismic-reflection Data. Bull. Geol. Soc. Am. 114 (2): 169-177.

Doi: 10.1130/0016-7606(2002) 1 1 4<0169:LSASOT>2.0.CO;2.

[10] S. Demirel, B. Alpar, C. Yaltırak, D. Vardar, and H. Kurt. 2020 Northern Segment of the North Anatolian Fault in the Gulf of Izmit Inferred from Marine Magnetic Anomalies. Mar. Geophys. Res. 41 (6). Doi: 10.1007/s1 1001-020-09399-6.

[11] F. Cultrera et al. 2017. Structural Architecture and Active Deformation Pattern in the Northern Sector of the AeolianTindari-Letojanni Fault System (SE Tyrrhenian Sea-NE Sicily) from Integrated Analysis of Field. Marine Geophysical, Seismological and Geodetic Data. Ital. J. Geosci. 136: 399417. Doi: 10.3301/IJG.2016.17.

[12] K. A. Kamesh Raju, G. P. S. Murty, D. Amarnath, and M. L. M. Kumar. 2007. The West Andaman fault and Its Influence on the Aftershock Pattern of the Recent Megathrust Earthquakes in the Andaman-Sumatra Region. Geophys. Res. Lett. 34(3).

Doi: 10.1029/2006GL028730.

[13] S. Wada et al. 2017. Continuity of Subsurface Fault Structure Revealed by Gravity Anomaly: The Eastern Boundary Fault Zone of the Niigata Plain, Central Japan. Earth, Planets Sp. 69(1): 15. Doi: 10.1186/s40623-017-0602-x.

[14] A. Lenhart, C. A.-L. Jackson, R. E. Bell, O. B. Duffy, R. L. Gawthorpe, and H. Fossen. 2019. Structural Architecture and Composition of Crystalline Basement Offshore West Norway. Lithosphere. 11 (2): 273-293. Doi: 10.1130/L668.1.

[15] S. J. Kaye and J. S. Milsom. 1988. Report on the Gravity and Magnetic Survey of the Tanimbarand Kai Islands, Eastern Indonesia University College London, Gravity Research Group. Report.

[16] S. Chatterjee, R. Bhattacharyya, L. Michael, K. S. Krishna, and T. J. Majumdar. 2007. Validation of ERS-1 and HighResolution Satellite Gravity with in-situ Shipborne Gravity over the Indian Offshore Regions: Accuracies and Implications to Subsurface Modeling. Mar. Geod. 30(3): 197-216. Doi: $10.1080 / 01490410701438323$

[17] D. H. Lee and T. D. Acharya. 2017. Comparison of Complete Bouguer Anomalies from Satellite Marine Gravity Models with Ship-borne Gravity Data in East Sea, Korea. J. Mar. Sci. Technol. 25(6): 625-632. Doi: 10.6119/JMST-017-1226-01.

[18] M. Yanis, M. Marwan, and N. Kamalia. 2020. Aplikasi Satellite GEOSAT dan ERS sebagai Metode Alternatif
Pengukuran Gravity Ground pada Cekungan Hidrokarbon di Pulau Timur. Maj. Geogr. Indones. 33(2).

Doi: 10.22146/mgi.50782.

[19] M. Yanis and Marwan. 2019. The Potential Use of Satellite Gravity Data for Oil Prospecting in Tanimbar Basin, Eastern Indonesia. IOP Conf. Ser. Earth Environ. Sci. 364(1): 012032. Doi: 10.1088/1755-1315/364/1/012032.

[20] M. Yanis, M. Marwan, and N. Ismail. 2019. Efficient Use of Satellite Gravity Anomalies for Mapping the Great Sumatran Fault in Aceh Province. Indones. J. Appl. Phys. 9(02): 61 . Doi: $10.13057 /$ ijap.v9i2.34479.

[21] R. A. Surya, F. Abdullah, D. Darisma, M. Yanis, and N. Ismail. 2019. Sedimentation process in Kuala Gigieng Coast, Aceh Besar based on Magnetic and Gravity Surveys. IOP Conf. Ser. Earth Environ. Sci. 348(1): 012040.

Doi: 10.1088/1755-1315/348/1/012040.

[22] N. Ismail, M. Yanis, F. Abdullah, A. Irfansyam, and B. S. W. Atmojo. 2018. Mapping Buried Ancient Structure using Gravity Method: A Case Study from Cot Sidi Abdullah, North Aceh. J. Phys. Conf. Ser. 1120: 012035. Doi: 10.1088/1742-6596/1120/1/012035.

[23] M. A. McLean, C. J. L. Wilson, S. D. Boger, P. G. Betts, T. J. Rawling, and D. Damaske. 2009. Basement Interpretations from Airborne Magnetic and Gravity Data Over the Lambert Rift Region of East Antarctica. J. Geophys. Res. Solid Earth. 114: B6.

Doi: 10.1029/2008JB005650.

[24] H. Silvennoinen and E. Kozlovskaya. 2007. 3D Structure and Physical Properties of the Kuhmo Greenstone Belt (Eastern Finland): Constraints from Gravity Modelling and Seismic Data and Implications for the Tectonic Setting. J. Geodyn. 43(3): 358-373.

Doi: 10.1016/j.jog.2006.09.018.

[25] M. Radhakrishna, S. Lasitha, and M. Mukhopadhyay. 2008. Seismicity, Gravity Anomalies and Lithospheric Structure of the Andaman Arc, NE Indian Ocean. Tectonophysics. 460(1-4): 248-262.

Doi: 10.1016/j.tecto.2008.08.021.

[26] D. Fernández-Blanco, M. Philippon, and C. Von Hagke, 2016. Structure and Kinematics of the Sumatran Fault System in North Sumatra (Indonesia). Tectonophysics. 693: 453-464.

[27] L. P. G. and R. E. S. W.M. Telford. 1991. Applied Geophysics. Second Edition. Cambridge University Press.

[28] W. M. Telford, L. P. Geldart, and R. E. Sheriff. 1990. Applied Geophysics. Cambridge University Press.

[29] B. Oruç, I. Sertçelik, Ö. Kafadar, and H. H. Selim. 2013. Structural Interpretation of the Erzurum Basin, Eastern Turkey, using Curvature Gravity Gradient Tensor and Gravity Inversion of Basement Relief. J. Appl. Geophys. 88: 105-113. Doi: 10.1016/j.jappgeo.2012.10.006.

[30] D. T. Sandwell and W. H. F. Smith. 2009. Global Marine Gravity from Retracked Geosat and ERS-1 Altimetry: Ridge Segmentation Versus Spreading Rate. J. Geophys. Res. Solid Earth. 114: B01411.

Doi: 10.1029/2008JB006008.

[31] A. Salem, S. Furuya, E. Aboud, E. Elawadi, H. Jotaki, and K. Ushijima. 2005. Subsurface Structural Mapping Using Gravity Data of Hohi Geothermal Area, Central Kyushu, Japan.

[32] N. P. Rao et al. 2011. Structure and Tectonics of the Andaman Subduction Zone from Modeling of Seismological and Gravity Data. Intech Publisher, Rijeka, Croatia.

[33] X. Q. Ma and D. R. Watts. 1994. Terrain Correction Program for Regional Gravity Surveys. Comput. Geosci. 20(6): 961972 Doi: 10.1016/0098-3004(94)90037-X.

[34] G. Ma and L. Li. 2012. Edge Detection in Potential Fields with the Normalized Total Horizontal Derivative. Comput. Geosci. 41: 83-87.

Doi: 10.1016/j.cageo.2011.08.016.

[35] I. M. Ibraheem, M. Haggag, and B. Tezkan. 2019. Edge Detectors as Structural Imaging Tools Using Aeromagnetic Data: A Case Study of Sohag Area, Egypt. Geosci. 9(5): 
211.

Doi: 10.3390/geosciences9050211.

[36] L. Cordell and V. I. S. Grauch. 2008. Mapping Basement Magnetitation Zones from Aeromagnetic Data in the San Juan Basin, New Mexico. SEG Technical Program Expanded Abstracts. 246-247.

Doi: $10.1190 / 1.1826915$.
[37] M. Pirttijarvi, "Gravity interpretation and modeling software based on 3-D block models," User's Guid. to version, vol. 1,

[38] Marwan, M. Yanis, R. Idroes, and N. Ismail. 2019. 2D Inversion and Static Shift of MT and TEM Data for Imaging the Geothermal Resources of Seulawah Agam Volcano, Indonesia. Int. J. GEOMATE. 17(62): 173-180. Doi: $10.21660 / 2019.62 .11724$. 